\section{(2) OPEN ACCESS}

\title{
Improved outcomes following the implementation of a decompensated cirrhosis discharge bundle
}

\author{
Katherine Smethurst, ${ }^{1}$ Jennifer Gallacher, ${ }^{1}$ Laura Jopson, ${ }^{1}$ \\ Titilope Majiyagbe, ${ }^{1}$ Amy Johnson, ${ }^{1}$ Philip Copeman, ${ }^{1}$ Dina Mansour, ${ }^{2,3}$ \\ Stuart McPherson (iD) 1,3
}

\begin{abstract}
- Additional supplemental material is published online only. To view, please visit the journal online (http://dx.doi. org/10.1136/flgastro-2021102021).
\end{abstract}

${ }^{1}$ Liver Unit, Newcastle Upon Tyne Hospitals NHS Foundation Trust, Newcastle Upon Tyne, UK ${ }^{2}$ Gastroenterology, Gateshead Health NHS Foundation Trust, Gateshead, UK

${ }^{3}$ Translational and Clinical Research Institute, Newcastle University, Newcastle upon Tyne, UK

\section{Correspondence to}

Dr Stuart McPherson, Newcastle University, Newcastle upon Tyne, UK; stuart.mcpherson2@nhs.net

Received 5 October 2021 Accepted 29 November 2021

\section{A Check for updates}

(c) Author(s) (or their employer(s)) 2021. Re-use permitted under CC BY-NC. No commercial reuse. See rights and permissions. Published by BMJ.

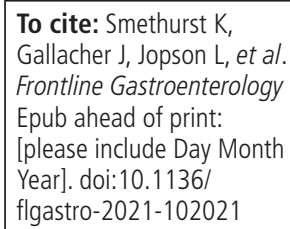

\section{ABSTRACT}

Introduction Mortality from liver disease is increasing and management of decompensated cirrhosis (DC) is inconsistent across the UK. Patients with DC have complex medical needs when discharged from hospital and early readmissions are common. Our aims were: (1) to develop a Decompensated Cirrhosis Discharge Bundle (DCDB) to optimise ongoing care and (2) evaluate the impact of the DCDB.

Methods $A$ baseline review of the management of patients with DC was conducted in Newcastle in 2017. The DCCB was developed and implemented in 2018. Impact of the DCDB was evaluated in two cycles, first a paper version (November 2018-October 2019) and then an electronic version (November 2020-March 2021). Key clinical data were collected from the time of discharge.

Results Overall, 192 patients (62\% male; median age 55; median model for endstage liver disease $17 ; 72 \%$ alcohol related) were reviewed in three cycles. At baseline, management was suboptimal, particularly ascites/diuretic management and provision of follow-up for alcohol misuse and $12 \%$ of patients had a potentially avoidable readmission within 30 days. After DCDB introduction, care improved across most domains, particularly electrolyte monitoring $(p=0.012)$ and provision of community alcohol follow-up ( $p=0.026)$.

Potentially preventable readmissions fell to $5 \%$ ( $p=0.055)$.

Conclusions Use of a care bundle for patients with DC can standardise care and improve patient management. If used more widely this could improve outcomes and reduce variability in care for patients with DC.

\section{INTRODUCTION}

There has been a rising incidence of liver disease in the UK over recent decades and

\section{Significance of this study}

What is already known on this topic

- Mortality rates from liver disease have risen substantially in the UK over the last few decades.

- There is wide variation in the management of patients with liver disease and this is reflected in outcomes and mortality.

- Patients with decompensated cirrhosis have complex hospital discharges and readmissions are common.

- Care bundles can help standardise the management of liver disease and improve outcomes

What this study adds

- Management of patients with cirrhosis was inconsistent at discharge and readmissions were common.

- A decompensated cirrhosis discharge bundle was developed to optimise hospital discharge with the aim of reducing variation in care. This bundle has now been endorsed by the British Society of Gastroenterology and the British Association for the Study of the Liver.

- Use of the bundle was associated with an improvement in the care of patients with decompensated cirrhosis at the time of hospital discharge.

\section{How might it impact on clinical} practice in the foreseeable future

- Wider implementation of this care bundle could improve outcomes for patients with cirrhosis, reduce avoidable readmissions and reduce variability in care.

this has been associated with a substantial increase in mortality. ${ }^{1}$ Decompensated cirrhosis (DC) is a common reason for hospital admission and carries a high risk of short-term mortality. ${ }^{2}$ Patients with cirrhosis are complex and frequently 
have multiple complications such as ascites, hepatic encephalopathy (HE) and varices that require ongoing management following hospital discharge. Importantly, multiple evidence-based treatments are available to treat liver-related complications, which have been shown to improve outcomes. ${ }^{3}{ }^{4}$ Despite their wide availability these treatments are frequently not initiated. This may be due either to them not being offered by clinicians or through non-engagement by patients, which may be partly due to patients not being provided adequate information about their condition. ${ }^{5}$ Alcohol remains the leading cause of liver disease in the UK and accounts for $60 \%$ of all cases. ${ }^{6}$ The National Confidential Enquiry into Patient Outcome and Death (NCEPOD) report (2013) showed significant variation in the provision of quality care for patients with alcohol-related liver disease (ARLD), with less than half of patients receiving 'good' care during hospital admission. $^{7}$

Due to the complex nature of patients with DC, hospital readmissions following discharge are common. The NCEPOD report found that 1752 patients amassed 7656 admissions in 2 years. $^{7}$ Ascites is the most common reason for readmission within 1 month, but this can largely be avoided by the effective use of day case paracentesis services. ${ }^{5}$ Other common reasons for readmission include electrolyte disturbance and acute kidney injury from over diuresis, which can be minimised by close monitoring of electrolytes and adjustment of diuretics. Moreover, both short-term and long-term mortality rates in patients with DC are high and readmission is an independent predictor of mortality. ${ }^{8}$ Therefore, processes need to be in place in all hospitals to ensure that patients receive appropriate follow-up monitoring and information about their condition prior to hospital discharge to improve outcomes.

One way of improving outcomes in patients with complex medical needs is using 'bundles' that prompt staff to follow guidelines. The British Society of Gastroenterology (BSG)/British Association for the study for the liver (BASL) 'Decompensated Cirrhosis Admission Bundle', which promotes a systematic approach to the management of DC for the first 24 hours, has been shown to improve care and shorten hospital stay. ${ }^{9} 10$

The overall aim of this service improvement project was to improve the quality of discharge of patients with DC, with the ultimate objective of reducing hospital readmissions and improving long-term outcomes.

Our specific aims were to:

1. To assess the quality of discharge in patients with DC and determine if discharge plans comprehensively addressed all patients' medical and social needs.

2. Determine the frequency of hospital readmissions and potentially preventable admissions.

3. Develop a 'decompensated cirrhosis discharge bundle (DCDB)' and a 'cirrhosis self-management toolkit' to standardise care on discharge and ensure that patients were well informed on their condition.

4. To assess the impact of implementation of the DCDB on patient outcomes

\section{METHODS}

Baseline review of the management of patients with DC at discharge

Consecutive patients discharged with DC (including Jaundice, ascites, variceal bleeding and HE) from the gastroenterology/hepatology wards at the Newcastle upon Tyne Hospitals NHS Foundation Trust (NUTH) were included from January to December 2017. Individual patients were only included once during the review period.

A comprehensive data collection tool was developed to review the management of cirrhotic complications at discharge based on the recommendations from the European Association for the Study of the Liver (EASL). ${ }^{4}$ A retrospective review of the patients' medical notes was undertaken to identify if specific aspects of their management were addressed at discharge, including management of ascites, varices, $\mathrm{HE}$, diuretics/electrolyte monitoring and alcohol harm reduction. In addition, we assessed 30-day readmission rates, including the presenting reason. 'Potentially preventable' readmissions were defined as those that we believe could have been avoided with improved discharge planning (eg, a patient presenting with ascites to the emergency department rather than having daycase elective paracentesis).

Development of the 'DCDB' and 'cirrhosis patient selfmanagement toolkit'

Following the baseline review, we developed the 'DCDB' to standardise the management of patients at the time of discharge (figure 1 and online supplemental file 1). This provides a perihospital discharge checklist to be completed by the ward medical staff to ensure that appropriate investigations and management are instituted according to EASL guidelines. Subsequently, the DCDB was reviewed by the BSG liver section and BASL and was endorsed following some minor modification. The BSG/BASL versions of the DCDB are available at https://wwwbsgorguk/clinical-resource/decompensated-cirrhosis-discharge-bundle.

Second, in collaboration with LIVErNORTH, our local liver patient charity, we developed a 'Cirrhosis patient self-management toolkit' (online supplemental file 2) to provide detailed information about cirrhosis to help patients and their caregivers to manage aspects of their care. This document includes helpful information to empower patients and encourage selfmanagement of complications such as HE and ascites.

Review of the impact of the implementation of the DCDB

The DCDB was implemented at NUTH in September 2018. All medical staff working on the gastroenterology/ 
This checklist should be completed by a member of the ward team. It should be started a minimum of 48 hours prior to discharge but can be done earlier and should be completed alongside the discharge letter. The information on the checklist should be reviewed on the consultant ward round prior to discharge.

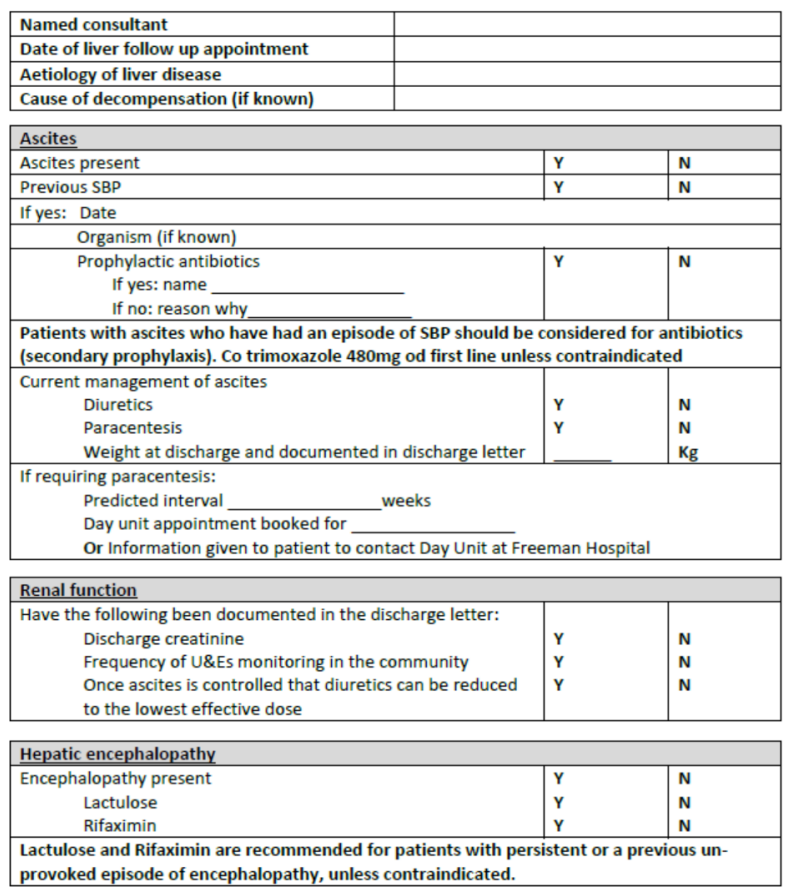

\begin{tabular}{|c|c|c|}
\hline \multicolumn{3}{|l|}{ Portal hypertension } \\
\hline Varices & $\mathrm{Y}$ & $\mathbf{N}$ \\
\hline Grade of varices & & \\
\hline Previous variceal bleed? & $\mathrm{Y}$ & N \\
\hline Is a repeat $O G D$ required? & $\mathbf{Y}$ & $\mathbf{N}$ \\
\hline If so, date booked for & & \\
\hline $\begin{array}{l}\text { Prophylaxis } \\
\text { Is patient on a B Blocker (carvedilol preferred) }\end{array}$ & & \\
\hline $\begin{array}{l}\text { Is patient on a B Blocker (carvedilol preferred) } \\
\text { If not, why not? }\end{array}$ & $\mathbf{Y}$ & N \\
\hline $\begin{array}{l}\text { Has advice been given about titrating dose? } \\
\text { (aim } H R \quad 60 / m i n \text { and } S B P>100 \text { ) }\end{array}$ & r & N \\
\hline Variceal band ligation & $\mathrm{Y}$ & $\mathbf{N}$ \\
\hline \multicolumn{3}{|c|}{$\begin{array}{l}\text { A repeat } O G D \text { is recommended at } 4 \text { weeks for those who have had variceal banding. } \\
\text { Non-selective } \beta \text { BBockers are recommended as primary prophylaxis for medium/large varices } \\
\text { and for small varices with red signs or Childs C cirrhosis. }\end{array}$} \\
\hline \multicolumn{3}{|l|}{ Substance / alcohol misuse } \\
\hline Alcohol misuse & $\mathrm{Y}$ & $\mathbf{N}$ \\
\hline Input from alcohol liaison team & $\mathrm{Y}$ & $\mathbf{N}$ \\
\hline Community follow up plans & $\mathrm{Y}$ & $\mathbf{N}$ \\
\hline Thiamine prescribed & $\mathrm{Y}$ & $\mathrm{N}$ \\
\hline \multicolumn{3}{|l|}{ Treatment plan } \\
\hline $\begin{array}{l}\text { If treatment limitations or palliative care have been decided, has } \\
\text { this been detailed in the discharge letter and does the patient } \\
\text { have an appropriate Treatment Escalation Plan or Emergency } \\
\text { Health Care Plan? }\end{array}$ & $\mathrm{Y}$ & $\mathbf{N}$ \\
\hline
\end{tabular}

\begin{tabular}{|l|l|l|}
\hline Communication with patient & \\
\hline Have the following been explained to the patient and/or family? & & N \\
The diagnosis of chronic liver disease & Y & N \\
The importance of abstinence (if applicable) & Y & N \\
Current medications and reasons for taking them & Y & N \\
Patient given the cirrhosis management toolkit leaflet & Y &
\end{tabular}

Figure 1 The decompensated cirrhosis discharge bundle. HR. hear-rate; OGD, oesophago-gastro-duodenoscopy; SBP, spontaneous bacterial peritonitis.

hepatology wards were given training on the DCDB and it was envisaged that the bundle would be used for all patients discharged with DC. The training included a presentation of the results of our baseline review and emphasised the areas requiring improvement. In addition, the training discussed the rationale and evidence base behind the recommendations contained within the DCCB. At the time of implementation, our medical notes were paper based, so a paper version was used. Following implementation, a review of the use of the DCDB and its impact was undertaken for consecutive patients discharged between November 2018 and October 2019 using similar methodology to the original review. In October 2019, our Trust moved to a completely electronic medical record so an electronic version of the DCDB was incorporated into the electronic patient record (eRecord, Cerner Millennium). Given the move to eRecord was a significant change in the way of working for staff, we waited several months to allow staff to become comfortable with the new system before conducting a further review. Further training on the electronic DCDB was undertaken with staff. A subsequent review of the use and impact of the electronic version of the DCDB was conducted on consecutive patients between November 2020 and March 2021 using the same methodology as previously.
Data analysis

Statistical analysis was performed using SPSS V.25.0. Fisher's exact test was used to determine differences in categorical variables between groups. A p $<0.05$ was considered statistically significant.

\section{RESULTS}

Description of the cohort

A total of 192 patient's records were reviewed across the 3 periods, 61 patients in the baseline review and 131 patients after bundle implementation. Overall, $62 \%$ of the cohort were male and the median age was 55 (range 22-89). The median Model for End-stage Liver Disease score for the cohort was 17 (range 6-38). ARLD was the most common aetiology of liver disease, accounting for $72 \%$ the total cohort. Overall, $70 \%$ had ascites and $43 \%$ had HE at the time of admission. Thirteen per cent of the cohort presented with variceal bleeding. There were no significant differences in the clinical characteristics or presenting features among patients in the three data collection periods.

Baseline review of the quality of discharge of patients with DC A summary of the management at hospital discharge of the 61 patients who were included in the baseline review is shown in table 1 . Overall, areas for improvement were identified, particularly the need to increase the proportion of patients with current alcohol misuse 
Table 1 A summary of the 61 patients who were included in the baseline review of the management of the patients at time of hospital discharge

\begin{tabular}{lc}
\hline Total patients (n) & 61 \\
\hline Patients with current alcohol misuse & $59 \%(36)$ \\
\hline Alcohol team review & $64 \%(23)$ \\
\hline Thiamine prescribed & $94 \%(34)$ \\
\hline Community alcohol plan & $39 \%(14)$ \\
\hline Patients with HE-related admission & $49 \%(30)$ \\
\hline Lactulose prescribed & $93 \%(28)$ \\
\hline Rifaximin prescribed & $90 \%(27)$ \\
\hline Patients with ascites & $74 \%(45)$ \\
\hline Discharge creatinine documented in discharge summary & $2 \%(1)$ \\
\hline Documented plan for electrolyte monitoring in community & $24 \%(11)$ \\
\hline Patients presenting with variceal bleed & $8 \%(5)$ \\
\hline Treated with beta-blockers, and/or repeat gastroscopy & $100 \%(5)$ \\
booked or TIPSS & \\
\hline Readmission within 30 days & $30 \%(18)$ \\
\hline Potentially preventable liver related 30-day readmission & $11 \%(7 / 61)$ \\
\hline HE, hepatic encephalopathy; TIPSS, transcutaneous intrahepatic \\
portosystemic shunt.
\end{tabular}

who were reviewed by the alcohol team and to better document plan for follow-up with the community alcohol team. In addition, there was a clear need to improve communication with primary care regarding plans for electrolyte monitoring, which were inadequate with only $24 \%$ having a documented recommendation for electrolyte monitoring and only $2 \%$ of patients having their discharge creatinine noted.

The overall 30-day readmission rate was high at $30 \%(18 / 61)$, with a high proportion of these being potentially preventable at $12 \%(7 / 61)$. All preventable readmissions were patients presenting with recurrent ascites who could have been treated with a planned day case large volume paracentesis.

\section{Review of the impact of implementation of the DCDB}

A total of 131 patients were reviewed following implementation of the DCDB, 86 when the bundle was in paper format and 45 using the electronic version. In the first review period, only 23 out of 86 (27\%) patients had the DCDB completed. Completion rates increased to $69 \%(31 / 45)$ when the electronic version was introduced.

Table 2 shows the comparison of the clinical management of patients at hospital discharge between those with and without a completed DCDB, including patients from all three review periods. Overall, use of the DCDB was associated with improvements in most aspects of care, with statistically significant improvements in the proportion of patients having an alcohol liaison review ( $85 \%$ vs $66 \%, \mathrm{p}=0.044)$ and community alcohol team follow-up (62\% vs 39\%, $\mathrm{p}=0.026)$. Moreover, there were significant improvements in communication with primary care about electrolyte monitoring $(61 \%$ vs $36 \% \mathrm{p}=0.012)$ and improvement
Table 2 A comparison of the clinical management of patients at the time of hospital discharge in patients with and without a completed DCDB

\begin{tabular}{|c|c|c|c|}
\hline & DCDB $n=54$ & $\begin{array}{l}\text { No DCDB } \\
n=138\end{array}$ & $P$ value \\
\hline $\begin{array}{l}\text { Patients with current alcohol } \\
\text { misuse }\end{array}$ & $63 \%(34)$ & $64 \%(88)$ & 0.917 \\
\hline Alcohol team review & $85 \%(29)$ & $66 \%(58)$ & 0.044 \\
\hline Thiamine prescribed & $91 \%(31)$ & $85 \%(75)$ & 0.552 \\
\hline Community alcohol plan & $62 \%(21)$ & $39 \%(34)$ & 0.026 \\
\hline $\begin{array}{l}\text { Patients with HE-related } \\
\text { admission }\end{array}$ & $30 \%(16)$ & $42 \%(58)$ & 0.138 \\
\hline Lactulose prescribed & $94 \%(15)$ & $91 \%(53)$ & 1.0 \\
\hline Rifaximin prescribed & $94 \%(15)$ & $84 \%(49)$ & 0.679 \\
\hline Patients with ascites & $70 \%(38)$ & $69 \%(95)$ & 0.886 \\
\hline $\begin{array}{l}\text { Discharge creatinine } \\
\text { documented in discharge } \\
\text { summary }\end{array}$ & $66 \%(25)$ & $6 \%(6)$ & $<0.001$ \\
\hline $\begin{array}{l}\text { Documented plan for electrolyte } \\
\text { monitoring in community }\end{array}$ & $61 \%(23)$ & $36 \%(34)$ & 0.012 \\
\hline $\begin{array}{l}\text { Patients presenting with variceal } \\
\text { bleed }\end{array}$ & $15 \%(8)$ & $11 \%(15)$ & 0.464 \\
\hline $\begin{array}{l}\text { Treated with beta-blockers, and/ } \\
\text { or repeat gastroscopy booked } \\
\text { or TIPSS }\end{array}$ & $100 \%(8)$ & $89 \%(13)$ & 0.526 \\
\hline Readmission within 30 days & $31 \%(17)$ & $25 \%(35)$ & 0.470 \\
\hline $\begin{array}{l}\text { Potentially preventable liver } \\
\text { related 30-day readmission }\end{array}$ & $4 \%(2)$ & $7 \%(10)$ & 0.407 \\
\hline
\end{tabular}

$D C D B$, decompensated cirrhosis discharge bundle; HE, hepatic encephalopathy; TIPSS, transcutaneous intrahepatic portosystemic shunt.

in documentation of creatinine in the discharge summary ( $66 \%$ vs $6 \% \mathrm{p}<0.001)$. Overall readmission rates and potentially preventable admissions were similar between patients with and without a completed bundle. When compared with the baseline review, however, there was a trend towards fewer potentially preventable readmissions after implementation of the DCDB whether or not the bundle was used $(7 / 61$ $(12 \%)$ vs $5 / 131(4 \%), p=0.055)$.

A breakdown of patient management for the three review periods reported separately is shown in table 3 . This shows that patients with a DCDB had numerically higher rates of appropriate management at discharge in most aspects of care when compared with those without a bundle and those in the baseline review, but numbers were too small to perform statistical analysis on these groups.

\section{DISCUSSION}

Multiple reports have shown that the care provided to patients with liver disease in the UK is variable and does not consistently meet the recommended standards set out by international guidelines. ${ }^{15711}$ Due to the complex nature of patients with DC, admissions are frequently prolonged and discharge planning can be complex, with the need for ongoing treatment 


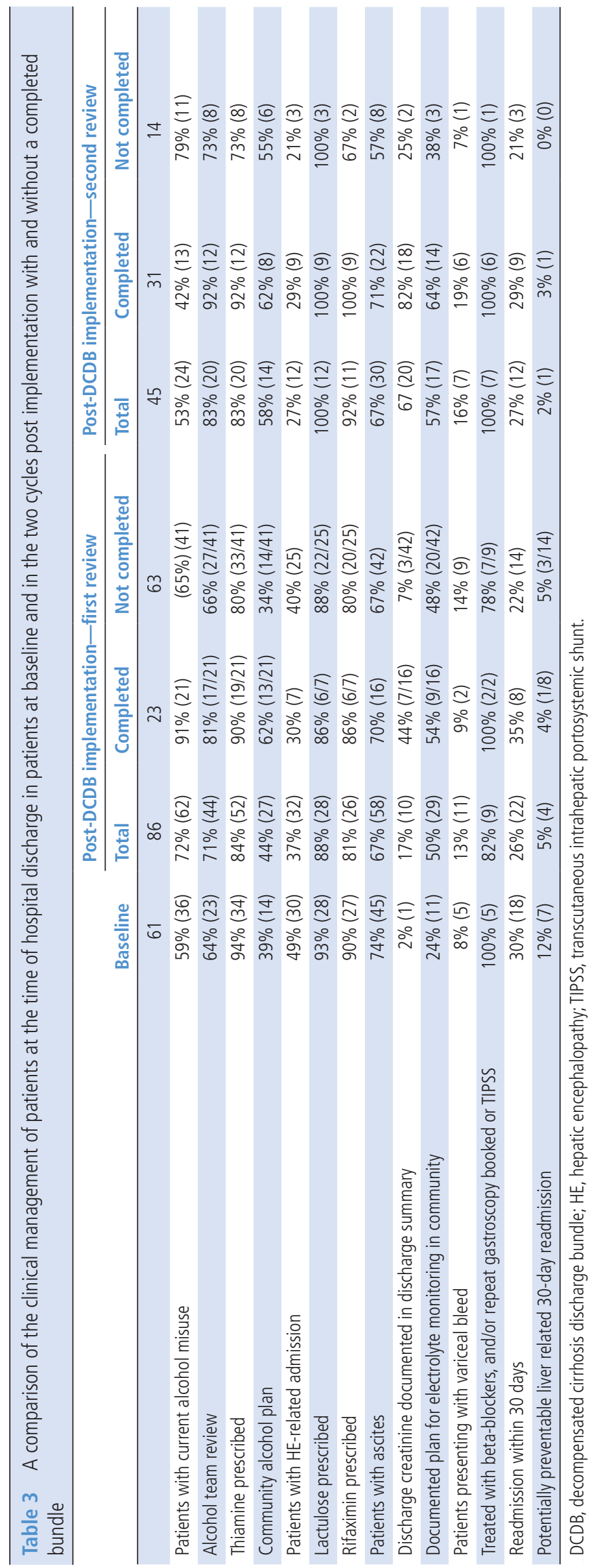


and monitoring in the community. Given, the BSG/ BASL Decompensated Cirrhosis Admission Bundle successfully improved outcomes for patients during their hospital admission, ${ }^{9}{ }^{10}$ we developed a bundle to improve management of patients with DC at hospital discharge and have evaluated its impact.

A baseline review of the quality of discharge following an admission with DC showed areas for improvement. We found a high potentially avoidable readmission rate of $12 \%$, primarily due to patients being readmitted with ascites requiring paracentesis when this procedure could have been performed as a planned outpatient procedure. In addition, some aspects of management were inadequate including documentation of alcohol team reviews, linking patients up with community alcohol services and failure to recommend ongoing monitoring of electrolytes. Given the wide variability in care and outcomes from liver disease identified in the Atlas of Variation on Liver disease, it is likely that deficiencies occur in the management of patients with DC in other hospitals that could be improved. ${ }^{11}$

After implementation of the DCDB (figure 1), we found that patients with a completed DCDB were more likely to have important aspects of care completed or documented, particularly the provision of harm reduction from alcohol and electrolyte monitoring, which were inadequate in the baseline review. Wider implementation of the DCDB could improve outcomes in other hospitals and help to reduce variability in care.

One of the aims of the bundle was to reduce avoidable readmissions. Interestingly, although we found no difference in the avoidable readmission rate between those with and without a completed DCDB, there was a trend $(p=0.055)$ towards fewer avoidable readmission after implementation of the bundle (with or without DCDB) compared with the baseline review. This could be due to patients being provided better information about cirrhotic complications with the self-management toolkit, which was likely to be given to most patients even if they did not have a completed DCDB. This toolkit encourages patients to arrange a paracentesis directly with our day treatment centre when required. Another explanation may be that this work generally raised the profile of improving the care of patients with DC in the department, potentially attenuating differences between those with and without a bundle. Moreover, the small sample size may have not been sufficient to detect a difference.

One of the frustrating aspects of this quality improvement project was that after initial implementation only $27 \%$ of patients had a completed bundle in the first assessment. This was a similar pattern to what was observed when we first introduced the DC admission bundle in Newcastle; in that project only $25 \%$ of patients had a completed bundle in the first cycle. However, completion rates increased to $90 \%$ after three cycles in that project. ${ }^{10}$ This emphasises the challenges of implementing 'change' in working practices, and shows perseverance, consistent feedback and re-education are required to implement change. In the current work, completion rates improved to $69 \%$ in the second cycle with the electronic version, but this remains below desirable levels. Further work is ongoing with the aim of achieving $>90 \%$ completion rates. We hope that this data showing improved outcomes associated with use of the bundle will convince the whole team of its benefits and promote its use.

Our study did have some limitations. First, as with all projects that use a retrospective case note review methodology, data collected relies on what has been documented in the notes, which may not be entirely reflective of patient's actual management, but the methodology used was consistent throughout the review period. Second, the overall study cohort was small, particularly those who had a completed bundle, which means strong conclusions cannot be made from these results. Moreover, there were small numbers of patients in many of the subgroups, so we were unable to undertake a more detailed statistical analysis of the cohorts. In addition, patient numbers were too small to assess any impact on long term outcomes such as mortality. Now that the DCDB has been endorsed by the BSG and BASL, we hope to further assess of the impact of the DCDB on larger scale with a multicentre audit to make more definitive conclusions.

In conclusion, management of DC at the time of hospital discharge is variable, with areas that require improvement. We developed a DCDB to standardise the provision of evidence-based care at discharge and this improved outcomes. If implemented more widely, the DCDB could help reduce variability in care and improve outcomes in patients with DC.

Twitter Titilope Majiyagbe@t_lexie, Dina Mansour@drdina_ mansour and Stuart McPherson @stumcp

Contributors KS: data collection, data analysis, writing of first draft of manuscript. JG: data collection, data analysis, writing of first draft of manuscript. LJ: codeveloped the bundle, data collection, data analysis. TM: data collection. AJ: codeveloped patient self-management toolkit, data collection. PC: data collection. DM: codeveloped the bundle, revised manuscript. SM: project lead, codeveloped the bundle and toolkit, data analysis, writing of manuscript, guarantor.

Funding LIVErNORTH for their support producing the Decompensated Cirrhosis Patient Self-Management Toolkit. SM is supported by a Medical Research Council CARP grant.

Competing interests SM: consultancy/speakers fees-Abbvie, Allergan, BMS, Gilead, Intercept, MSD, Novo Nordisk, Norgine, Novartis, Sequana. DM: consultancy-intercept.

Patient consent for publication Not applicable.

Ethics approval This study involves human participants but was exempt as it was a retrospective service improvement project. The project was approved by the Newcastle upon Tyne Hospitals NHS Foundation Trust clinical governance department (project number 8505).

Provenance and peer review Not commissioned; externally peer reviewed. 
Data availability statement All data relevant to the study are included in the article or uploaded as online supplemental information. Not applicable.

Supplemental material This content has been supplied by the author(s). It has not been vetted by BMJ Publishing Group Limited (BMJ) and may not have been peer-reviewed. Any opinions or recommendations discussed are solely those of the author(s) and are not endorsed by BMJ. BMJ disclaims all liability and responsibility arising from any reliance placed on the content. Where the content includes any translated material, BMJ does not warrant the accuracy and reliability of the translations (including but not limited to local regulations, clinical guidelines, terminology, drug names and drug dosages), and is not responsible for any error and/or omissions arising from translation and adaptation or otherwise.

Open access This is an open access article distributed in accordance with the Creative Commons Attribution Non Commercial (CC BY-NC 4.0) license, which permits others to distribute, remix, adapt, build upon this work noncommercially, and license their derivative works on different terms, provided the original work is properly cited, appropriate credit is given, any changes made indicated, and the use is noncommercial. See: http://creativecommons.org/licenses/by-nc/4. $0 /$.

\section{ORCID iD}

Stuart McPherson http://orcid.org/0000-0002-5638-2453

\section{REFERENCES}

1 Williams R, Aspinall R, Bellis M, et al. Addressing liver disease in the UK: a blueprint for attaining excellence in health care and reducing premature mortality from lifestyle issues of excess consumption of alcohol, obesity, and viral hepatitis. Lancet 2014;384:1953-97.
2 McPherson S, Lucey MR, Moriarty KJ. Decompensated alcohol related liver disease: acute management. $B M$ J 2016;352:i124.

3 Mansour D, McPherson S. Management of decompensated cirrhosis. Clin Med 2018;18:s60-5.

4 Angeli P, Bernardi M, Villanueva C, et al. EASL clinical practice guidelines for the management of patients with decompensated cirrhosis. J Hepatol 2018;69:406-60.

5 Williams R, Aithal G, Alexander GJ, et al. Unacceptable failures: the final report of the Lancet Commission into liver disease in the UK. Lancet 2020;395:226-39.

6 British Liver Trust. Statistics, 2021. Available: https:// britishlivertrust.org.uk/about-us/media-centre/statistics/ [Accessed 10 May 2021].

7 NCEPOD. "Measuring the Units"-a review of patients who died with alcoholic related liver disease. National Confidential Enquiry into Patient Outcome and Death (UK) 2013:1-25.

8 Scaglione SJ, Metcalfe L, Kliethermes S, et al. Early hospital readmissions and mortality in patients with decompensated cirrhosis enrolled in a large National health insurance administrative database. J Clin Gastroenterol 2017;51:839-44.

9 McPherson S, Dyson J, Austin A, et al. Response to the NCEPOD report: development of a care bundle for patients admitted with decompensated cirrhosis-the first $24 \mathrm{~h}$. Frontline Gastroenterol 2016;7:16-23.

10 Dyson JK, Rajasekhar P, Wetten A, et al. Implementation of a 'care bundle' improves the management of patients admitted to hospital with decompensated cirrhosis. Aliment Pharmacol Ther 2016;44:1030-8.

11 NHS liver care. NHS atlas of variation for people with liver disease: reducing the unwanted variation to increase value and improve quality. Right Care 2013:1-141. 